\title{
Exploitation of Online Social Networks (OSNs) among University Students: A Case Study of the University of Dodoma
}

\author{
Deo Shao \\ Virtual Education Technology and Applications \\ The University of Dodoma \\ Dodoma, Tanzania
}

\author{
Hassan Seif \\ Computer Science \\ The University of Dodoma \\ Dodoma, Tanzania
}

\begin{abstract}
Online Social Networks (OSNs) pervades all aspects of modern society, particularly with the tremendous developments of mobile technologies. This study surveys the exploitations of Online Social Networks for educational purposes by the students at the University of Dodoma (UDOM). A sample student from each college was taken and a questionnaire survey was administered to get the response from the students. The responses show that many social media applications such as Facebook, Twitter, Google+, Blogs and Wikis are frequently used by the responded students for communication, class activities, online learning and connecting with instructors. In general, the acceptance of OSNs by University students alerts that OSNs has the power to expand the walls of the classroom, expose students to the great thinkers of the world, and give them a voice in both local and global conversations. The findings of this study will help build a baseline for future investigations on exploiting social media for improving education delivery systems in Tanzania.
\end{abstract}

\section{General Terms}

Education, Technology

\section{Keywords}

Social media, Social networks, Web 2.0, University students, The University of Dodoma.

\section{INTRODUCTION}

Online Social Networks (OSNs) has been gaining popularity by attracting millions of users, many of whom have integrated them into their daily practices. These platforms are becoming trendy among students and professionals and help them in connecting with each other, their local and the global community at large [1]. A tremendous increase in the use of social networks in Tanzania has also been observed but yet no study has been conducted for assessing the use of these social media among university students. This study investigates the exploitation of Online Social Networks for educational purposes by the students at the University of Dodoma.

\section{BACKGROUND OF THE STUDY}

Over the past few years the world has witnessed a tremendous growth of web-technologies ranging from computer based to mobile based applications. The new generation Social media, popularly known as Web 2.0 is becoming a central topic in our information world. According to O'Reilly [2], Social network can be defined as "the network as platform, spanning all connected devices; social media applications are those that make the most of the built-in advantages of that platform: delivering software as a continually-updated service that gets better the more people use it, consuming and remixing data from multiple sources, including individual users, while providing their own data and services in a form that allows remixing by others, creating network effects through an 'architecture of participation,' and going beyond the page metaphor of Web 1.0 to deliver rich user experiences".

Also according to Helou and Rahim [3]; Social networking websites are virtual communities which allow people to connect and interact with each other on a particular subject or to just "hang out" together online.

There are several social media that build the social networks, such as Blogs, Wikis, RSS feeds, Instant messaging (IM) and Multimedia files sharing networks. Error! Not a valid bookmark self-reference. presents the descriptions of the social media.

Table 1: Social Media applications

\begin{tabular}{|c|c|c|}
\hline Social Media & Description & Example \\
\hline Wikis & $\begin{array}{c}\text { Wikis enables the } \\
\text { publication of collaborative } \\
\text { creative contents and } \\
\text { allows multiple users from } \\
\text { all over the world to build } \\
\text { knowledge base. }\end{array}$ & Wikipedia \\
Wikihow & \\
\hline Blogs and & $\begin{array}{c}\text { The blogs are new and } \\
\text { easy process of publishing } \\
\text { the ideas on the web and to } \\
\text { get the comments from } \\
\text { other web surfers }\end{array}$ & $\begin{array}{c}\text { Wordpress } \\
\text { Blogger }\end{array}$ \\
\hline $\begin{array}{c}\text { Instant } \\
\text { messaging } \\
\text { (IM) }\end{array}$ & $\begin{array}{c}\text { IM is a type of } \\
\text { communications service } \\
\text { that enables } \\
\text { private communication } \\
\text { between individuals or } \\
\text { group of individuals. }\end{array}$ & $\begin{array}{c}\text { Whatsapp, } \\
\text { Viber, } \\
\text { Telegram, } \\
\text { BBM, Sype } \\
\text { Facebook, } \\
\text { twitter }\end{array}$ \\
\hline $\begin{array}{c}\text { Multimedia } \\
\text { files sharing }\end{array}$ & $\begin{array}{c}\text { These are applications that } \\
\text { enable sharing video and } \\
\text { audio clips through } \\
\text { internet. }\end{array}$ & $\begin{array}{c}\text { YouTube, } \\
\text { Sound-Cloud, } \\
\text { hulk-share, } \\
\text { vimeo }\end{array}$ \\
\hline & \multicolumn{2}{c}{} \\
\hline
\end{tabular}

In recent years, social media such as Facebook, twitter, Instagram and Youtube have become popular particularly with university students. These applications have become part of the students' lives and help to build their connections with others. These connections are based on related interests, work, interactions and personal relationships. Experts put it forward that social media applications have a great potential to 
promote online learning [4]. With social media, educators can now much more readily connect with their students.

\section{RELATED WORKS}

A review of literature reveals that these emerging technologies are increasingly being adopted by students in academic institutions and may have a major effect on existing teaching and learning practices. Keeping this reality in view, researchers in academic and professional institutions have studied the use of these social media applications among students in recent years.

A study by Mohd et. al [5] on the use of Web 2.0 applications by the students in Malaysia report that students are comfortably using social media for learning. The analysis of data gathered gives hope on leveraging social media to improve the education system in developing country.

Similar study by Kaveri et. al [6] stipulates that social media could promote and research skills in a world where knowledge construction and dissemination make increasing use of online information networks. Thus, these social media are suitable for educational and lifelong learning purposes in our knowledge society, because our modern society is built to a large degree on digital environments of work and social communication.

According to a study carried by Khedo et.al [7] about OSNs as a tool to enhance learning in the Mauritian Education System, it was found that most of students (55.7\%) agreed that OSNs is beneficial to their studies while a smaller number of respondents did not agree on this. However Ndidi et.al [8] reported that; though students devote their times on the OSNs but majority of them are not affected academically ( about $42 \%$ ), $32 \%$ affected negatively while only $26 \%$ affected positively.

Furthermore, a study by Cheung and Chiu [9] about the influence of social networking sites on students' academic performance in Malaysia, it was found that the majority of the respondents agreed that social networking sites have a positive impact on their academic performance; despite the fact that they also reported that, they mainly engaged in social networking sites for social reasons rather than academic reasons. A study by Hassan and Shamim [10], stipulate that, OSNs have all components of fostering modern learning by promoting interdependent, personalized learning, learner centered in the process of acquiring knowledge

\section{METHODOLOGY}

The instrument used for data collection of this study was the questionnaire. The questionnaire had both open and close ended questions. This was because of the nature of information which were needed and the form of analysis to be conducted. A 7-questions structured questionnaire was designed and administered to students from six different colleges found at UDOM. The colleges include: College off informatics and virtual education (CIVE), College of Education (CoED), College of Humanities and Social Sciences (CHSS), College of Natural and Mathematics Sciences (CNMS), College of Health Sciences (CHS) and lastly College of Earth Sciences (CoES). The questionnaire was designed by observing anonymity so as to enable the student fill them truthfully without fear of intrusion of privacy.

The population of this study was the totality of all number of students found at UDOM. The data was collected from 178 students. Gathered response was statistically analysed using descriptive statistics like frequencies, percentages and graphs, with the help of Statistical Package for Social Science (SPSSVersion 16). Results of the data analysis are presented and discussed in result section.

\section{RESULTS AND DISCUSSIONS}

The results show that of the 178 respondents, $82.6 \%$ were male and $17.4 \%$ were female.

\subsection{Usage of Social Media among Respondents}

To assess this, the respondents were asked on the frequency of using social media. This might be several times a day, once a day, 1-2 times a week, less than 1-2 times a week, never or hardly ever. The results show that; Twitter is mostly used by students in several times a day (about $61.3 \%$ of respondents) followed by Dropbox (about 53.8.6\%) while Linkedln was the last one (about 30\%). Furthermore Google+ is mostly never or hardly ever used by students (about $38.0 \%$ of respondents) while Twitter was the last one (about $16.1 \%$ ).

Figure 1 summarizes the overall usage of social media applications

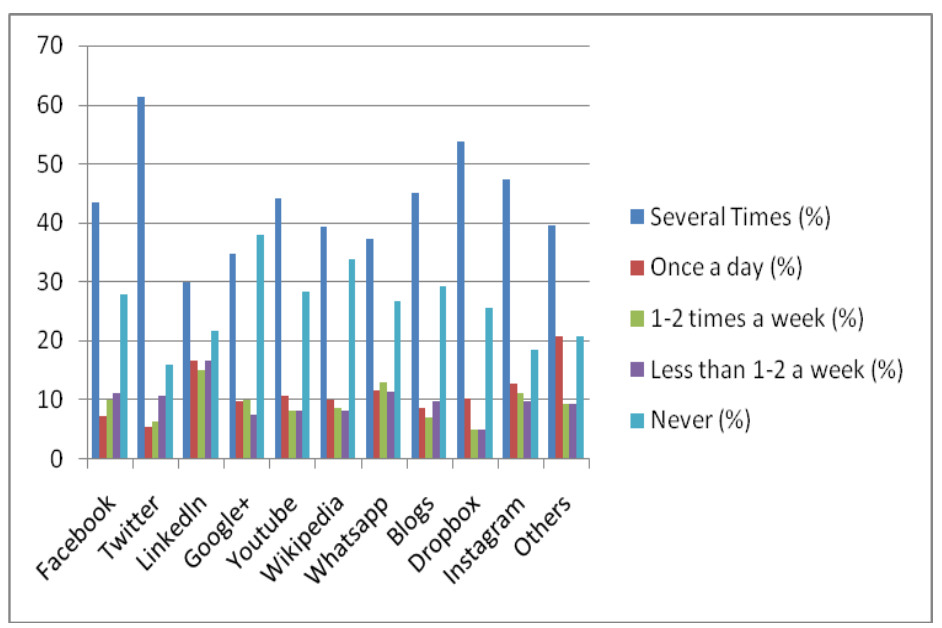

Figure 1: Frequency use of Social Media among respondent

Also it was found that, most of the students when they login into these social media applications their main purpose were to keep in contact with friends and family easier. This can be depicted in Table 2 . About $40.8 \%$ uses OSNs to keep in contact with friends and family easier, $25.6 \%$ to connect with other students within University, $24.2 \%$ to discuss and share with other students learning materials, $9.3 \%$ to connect to lecturers for further learning help. The findings on Error! Reference source not found. and Figure 1 correlate with the findings of the study by conducted Sponcil and Gitimu [11].

Table 2: Activity when login into social media website

\begin{tabular}{|c|c|c|c|c|}
\hline & \multicolumn{2}{|c|}{ Responses } & $\begin{array}{c}\text { Percent } \\
\text { of } \\
\text { Cases }\end{array}$ \\
\hline Activity & $\begin{array}{c}\text { keep in contact } \\
\text { with friends and } \\
\text { family easier }\end{array}$ & 118 & $40.8 \%$ & $79.7 \%$ \\
\cline { 2 - 5 } & $\begin{array}{c}\text { Connect with } \\
\text { other students }\end{array}$ & 74 & $25.6 \%$ & $50 \%$ \\
\hline
\end{tabular}




\begin{tabular}{|c|c|c|c|c|}
\hline & within University & & & \\
\cline { 2 - 5 } & $\begin{array}{c}\text { Discuss and share } \\
\text { with other } \\
\text { students learning } \\
\text { materials }\end{array}$ & 70 & $24.2 \%$ & $47.3 \%$ \\
\cline { 2 - 5 } & $\begin{array}{c}\text { Connect to } \\
\text { lecturers for } \\
\text { further learning } \\
\text { help }\end{array}$ & 27 & $9.3 \%$ & $18.2 \%$ \\
\hline Total & & 289 & $100.0 \%$ & $195.3 \%$ \\
\hline
\end{tabular}

\subsection{Usage of Online Social Network for Learning}

It was found that, most of students have used OSNs for learning. About $78.95 \%$ of the respondents said yes when they were asked whether they have ever used Online Social Network for learning; while $21.05 \%$ said no. This can be depicted by Figure 2.

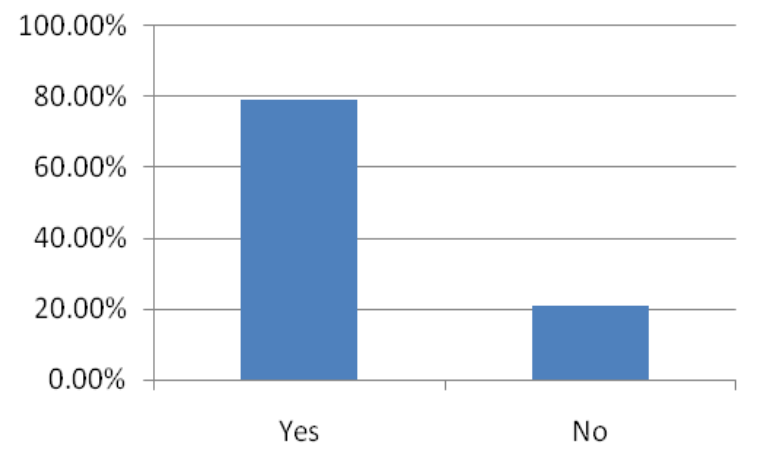

Figure 2: Response on usage of online social network for learning

Furthermore, it was found that most of the student prefer Google and Wikipedia for learning which accounts for $28.2 \%$ and $23.9 \%$ respectively. While the least preferred OSNs were Linkedln, Viber and Dropbox which accounts for $0.5 \%, 0.5 \%$ and $1.1 \%$ respectively. Figure 3 presents the summary of the usage of OSNs for learning.

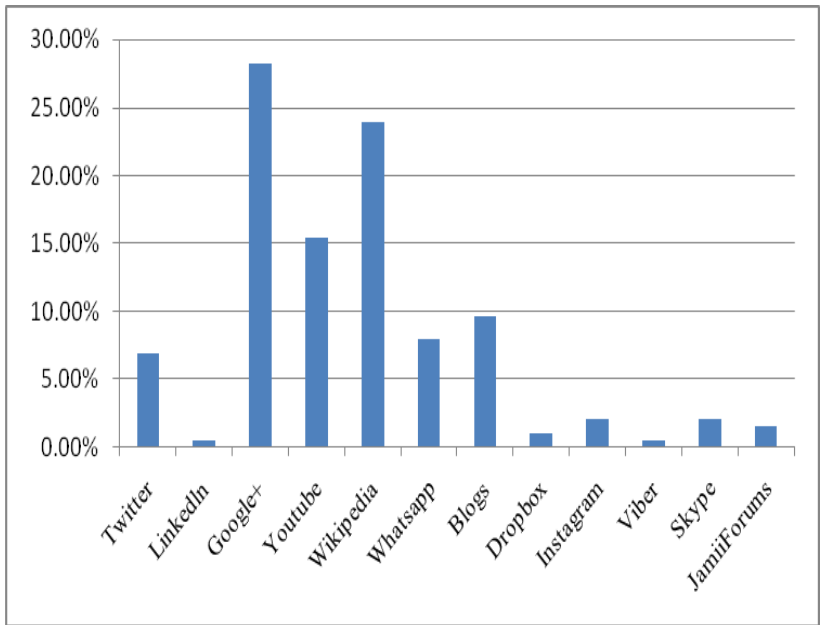

Figure 3: Response on which Social Network used for Learning
Regarding the effect of OSNs on educational performance, majority of the respondents agreed on improvement of performance on their study due to the presence of social networking website. This can be evidenced from the question which was asked whether the presence of OSNs help them to improve their performance in class or not? About $86.78 \%$ agreed that OSNs improve their performance in class while $13.22 \%$ disagreed. Figure 4 depicts the response regarding the use of OSNs on improving performance.

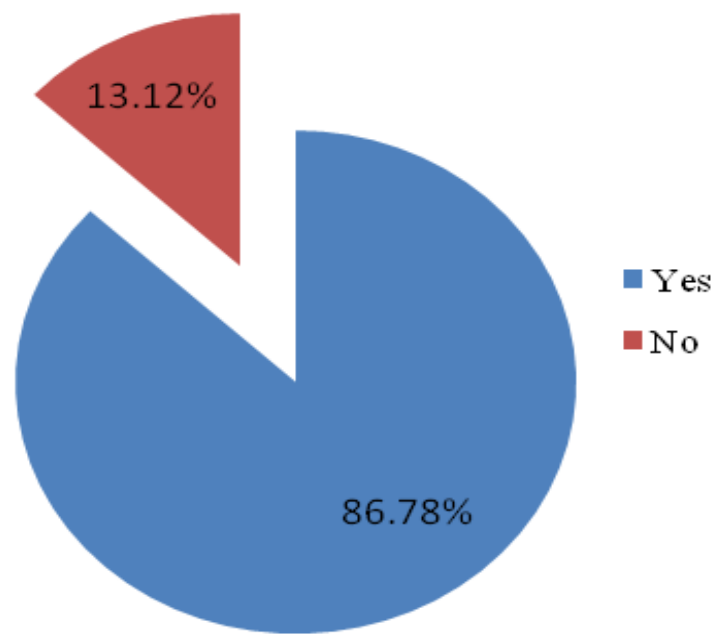

Figure 4: Response on whether social network help to improve student performance in a class

It was further found that, there are several learning activities that happen on OSNs. These learning activities are; searching for material $(33.87 \%)$, Discussion $(29.03 \%)$, Download material $(28.23 \%)$ and Reading online materials (8.87\%). Error! Reference source not found. shows the distribution of learning activities in OSNs. These data give hope that OSNs can be used to improve educational performance through online educational engagement which gives a proof on the result depicted on Error! Reference source not found. On the time students spends on OSNs, Pollara and Zhu [9] put forward that "If students are already investing time and energy in social networking, building relationships and their own communities of shared interests and fostering 21 st century skills in the process, there is a unique opportunity to form educational communities of knowledge". A worked example that leveraged OSNs is the London School of Business and Finance which offered an MBA through a Facebook application [10]. Another worked example at the Iowa University which used Facebook to engage students collaboration with their professors showed OSNs are tools that need to be taken serious in education sectors [14]. 


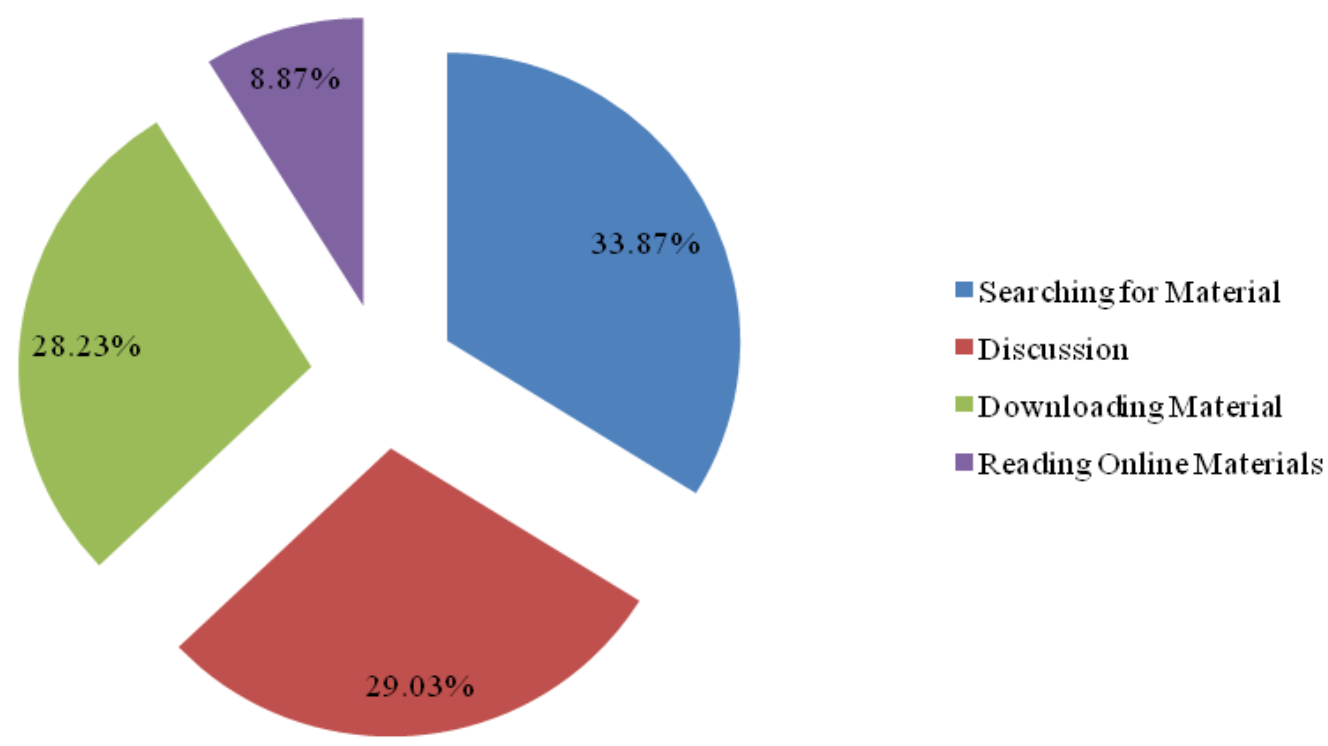

Figure 5: Learning activity performed by student in OSNs

\section{LEARNING THEORY AND OSNS}

Learning theories have an incredible impact on the use of OSNs in education. One particular theory is behaviorism. The advocates of behaviorism believe that the learner needs to be able to respond to external stimuli during the learning process. OSNs can provide the learner with external stimuli though comments from other OSNs users. According to Kioh et. al [12] on the social learning theory, people learn from one another via observation, imitation, and modeling. OSNs can provide the necessary motivation for learners and chances for reproduction of material and opportunities of retention of what they learn.

Another learning theory social constructivism accentuates culture and environment as a part of the learning process [13]. Learning is constructed through interactions with and among other students. OSNs provide an avenue for students to interact in an asynchronous place independent manner. Students are able to learn from the web-based environment around them and become a community of learners [14].

Several OSNs such as Facebook, Whatsapp and Google+ have features to allow users group creation and members can join to explore their interests and learn collaboratively. Therefore OSNs can play a role in cognitive constructivist approach by allowing students to learn in socially and cognitively rich environments. Collaborative learning has a great role in cognitive development [15].

\section{CONCLUSION}

The study presents general trends of social media usage among the students of the University of Dodoma. It was found that Wikipedia (15.9\%), Facebook (15.6\%), Google (14.6\%) and Youtube $(14.5 \%)$ are often used by students. The students seems to be equipped with latest web 2.0 tools and skills, so they were no any critical problem reported regarding the use of OSNs. However, this study recommends further investigation on security and privacy issues regarding the use of OSNs particularly for educational purposes. Although this survey is restricted to a group of University of Dodoma Students, the data obtained provide some insights into how students in Tanzania have been using the social media for both formal and informal learning and communication. It was found that, most of student use online social network for learning purpose. The most learning activity performed by students was searching for material related to their study. On the other hand, OSNs are leveraged by students to maintain contact with their friends and families easier (40.8\%). It is hoped that the findings described here will help to build a foundation for future investigations in Tanzania related to social media.

\section{FUTURE WORK}

While the first instinct in many Universities and Schools is often to block OSNs services such as Facebook and Twitter, the positives of these tools often outweigh the negatives. Universities should provide their students with reliable Internet connectivity to promote the use of OSNs among students. However, there should be efforts in monitoring the use of OSNs in campuses to ensure they are used to uplift educational outcomes. Moreover, universities should devise ways of integrating some of their teaching activities in OSNs. Educators should also be trained on how they can integrate social sites to improve their classes delivering modes. Educational leaders and policymakers should continuously look outside the classroom for technology-based approaches such as social media that will support access to educational resources. These will assure improved educational outcomes through extensive way of teaching and learning.

Future research studies should consider expanded samples from other Universities to examine the impact of diverse demographic characteristics on the exploitation of social media sites.

\section{ACKNOWLEDGMENTS}

We would like to that to thank all respondents for their participations in our survey. Furthermore, we would like to express our thanks to Mr. Abdsolam of COED, Mr. A.Sanga of COED and Mr. Mshindo Ally of CHSS for giving us access during data collection at their colleges. We further thank reviewers for their comments and inspirations on our work. 


\section{REFERENCES}

[1] J. Lee, K. Hall, and G. Gay, "Technology Acceptance and Social Networking in Distance Learning," Educational Technology, vol. 6, no. 2, pp. 50-61, 2003.

[2] O. Tim, "Web 2.0: Compact Definition?," 2005. [Online]. Available: http://radar.oreilly.com/2005/10/web-20-compactdefinition.html. [Accessed: 28-Feb-2014].

[3] A. Helou and N. Rahim, "The influence of social networking sites on students' academic performance in Malaysia," in International Conference on Internet Studies, Kuala Lampur, Malaysia. September 8, 2010, 2010, pp. 87-93.

[4] V. Sirje, "Use of Web 2.0 technologies in LIS education: experiences at Tallinn University, Estonia," Electronic library and information systems, , vol. 42, no. 3, pp. 262 $274,2008$.

[5] H. Z. Mohd, W. Jason, and L. E. Sylvia, "Investigating the use of Web 2.0 technology by Malaysian students," Multicultural Education \& Technology Journal, vol. 4, no. 1 , pp. $17-29,2010$

[6] M. R. Kaveri, Subrahmanyam Stephanie and E. Natalia, Waechter Guadalupe, "Online and offline social networks: Use of social networking sites by emerging adults," Journal of Applied Developmental Psychology, vol. 29 , no. 6 , pp. $420-433,2008$.

[7] K. K. Kavi, E. Sheik Mohammad Roushdat Ally, M. Asslinah, and S. Rajen, "Online Social Networking as a Tool to Enhance Learning in the Mauritian Education System," Journal of Emerging Trends in Computing and Information Sciences, , vol. 3, no. 6, pp. 907-912, 2012.

[8] C. Onyeka Ndidi, I. Sajoh Dahiru, and D. Bulus Lucy, "The Effect of Social Networking Sites Usage on the Studies of Nigerian Students," The International Journal Of Engineering And Science (IJES), vol. 2, no. 7, pp. 3946, 2013.

[9] C. M. K. Cheung and M. K. O. L. Pui-Yee Chiu, "Online social networks: Why do students use facebook?," Computer in Human Behaviour, vol. 27, no. 1, pp. 13371343, 2011
[10] A. Raihan, M. Hasan, and R. H. Shamim, "Facebook, The New Edutainment Avenue in TVET for Affective Learning," IOSR Journal of Engineering, vol. 3, no. 12, pp. 16-28, 2013.

[11] M. Sponcil and P. Gitimu, "Use of social media by college students: Relationship to communication and self-concept," Journal of Technology Research, vol. 1, no. 2, pp. 1-13, 2011.

[12] P. Pollara and Z. Jie, "Social Networking and Education : Using Facebook as an Edusocial Space," in Society for Information Technology \& Teacher Education International Conference 2011, 2011, vol. 2011, pp. $3330-3338$.

[13] Computerweekly.com, "London School of Business and Finance offers MBA on Facebook," computerweekly, $2014 . \quad$ [Online]. Available: http://www.computerweekly.com/news/1280094192/Lon don-School-of-Business-and-Finance-offers-MBA-onFacebook. [Accessed: 07-Apr-2014].

[14] S. Jacob and G. Thomas J., The Chemistry of Facebook: Using Social Networking to Create an Online Community for the Organic Chemistry Laboratory, vol. 54, no. 3. The Fischler School at Nova Southeastern University, 2009, pp. 1-10.

[15] K. Kioh, S. Jain, G. Westhoff, and L. Rezabek, "A quantitative exploration of preservice teachers' intent to Use computer-based technology," Journal of Instructional Psychology, vol. 3, no. 3, pp. 275-287, 2008.

[16] B. Kim, “Social Constructivism By," Emerging perspectives on learning, teaching, and technology, vol. 1, no. 1, pp. 1-6, 2001.

[17] R. Duit and D. Treagust F., Learning in Science-From Behavioursm Towards Social Constructivism and Beyond. Kluwer Academic Publishers, 1998, pp. 3-25.

[18] J. Piaget, The moral judgement of the child. London: , 1932. 